\title{
Health literacy of patients on oral anticoagulation treatment- individual and social determinants and effect on health and treatment outcomes
}

Ana Cristina Cabellos-García1,2, Antonio Martínez-Sabater ${ }^{3,4^{*}}$, Miguel Ángel Díaz-Herrera 5,6, Vicente Gea-Caballero ${ }^{2,7}$ and Enrique Castro-Sánchez ${ }^{8,9}$

\begin{abstract}
Background: Assessment health literacy in people with cardiovascular health problems would facilitate the development of appropriate health strategies for the care and reduction of complications associated with oral anticoagulation therapy. Aim: To evaluate the relationship between health literacy and health and treatment outcomes (concordance with oral anticoagulants, Normalized Ratio control and occurrence of complications) in patients with cardiovascular pathology.
\end{abstract}

Methods: Observational, analytic and cross-sectional study carried out on 252 patients with cardiovascular pathology (atrial fibrillation, flutter or valve prosthesis), aged 50-85 years, accessing primary care services in Valencia (Spain) in 2018-2019. Variables referring to anticoagulant treatment with vitamin K antagonists (years of treatment, adequate control, polypharmacy and occurrence of complications, among others) and health literacy (Health Literacy Questionnaire) were analysed.

Results: All dimensions of health literacy were significantly related to the level of education $(p<0.02)$, social class $(p<0.02)$, an adequate control of acenocoumarol $(p<0.001)$, frequentation of health services $(p<0.001)$, information by patients to health professionals about anticoagulant treatment $(p<0.03)$, emergency care visits $(p<$ $0.001)$ and unscheduled hospital admissions $(p<0.001)$.

Conclusion: Health literacy has a relevant influence on the adequate self-management of anticoagulation treatment and the frequency of complications. The different dimensions that comprise health literacy play an important role, but the "social health support" dimension seems to be essential for such optimal self-management.

Trial registration: ACC-ACE-2016-01. Registration date: December 2015.

Keywords: Health literacy, Anticoagulants, Acenocoumarol, Treatment adherence and compliance, Selfmanagement, Drug-related side effects and adverse reaction, Health services

\footnotetext{
* Correspondence: antonio.martinez-sabater@uv.es

${ }^{3}$ Nursing Department, Universitat de València, Valencia, Spain

${ }^{4}$ Facultat d'Infermeria i Podologia. Nursing Care and Education Research

Group. (GRIECE). Grupo Investigación en Cuidados (INCLIVA), Hospital Clínico

Universitario, Valencia, Spain

Full list of author information is available at the end of the article
}

C The Author(s). 2021 Open Access This article is licensed under a Creative Commons Attribution 4.0 International License, which permits use, sharing, adaptation, distribution and reproduction in any medium or format, as long as you give appropriate credit to the original author(s) and the source, provide a link to the Creative Commons licence, and indicate if changes were made. The images or other third party material in this article are included in the article's Creative Commons licence, unless indicated otherwise in a credit line to the material. If material is not included in the article's Creative Commons licence and your intended use is not permitted by statutory regulation or exceeds the permitted use, you will need to obtain permission directly from the copyright holder. To view a copy of this licence, visit http://creativecommons.org/licenses/by/4.0/. The Creative Commons Public Domain Dedication waiver (http://creativecommons.org/publicdomain/zero/1.0/) applies to the data made available in this article, unless otherwise stated in a credit line to the data. 


\section{Background}

Cardiovascular diseases are the leading cause of death worldwide. Atrial fibrillation (AF) is the most frequent arrhythmia, associated with high mortality and morbidity [1], and with an estimated prevalence in Spain of over $4.4 \%$. Therapeutic management of AF requires modification of cardiovascular risk factors and use of drugs $[1,2]$ such as oral anticoagulants (OAC). Among these, both vitamin $\mathrm{K}$ antagonists (VKAs) and direct oral anticoagulants (DOACs) are effective in preventing embolic events [2]. Because the anticoagulant effect of DOACs is difficult to quantify, continuous monitoring and education are necessary to ensure therapeutic follow-up, reflecting the complexity of DOACs use [3, 4].

The recommendations for switching from VKAs to DOACs due to the suboptimal control of the international normalized ratio (INR) were eased in Spain in 2012. At present, however, the legal requirement for a visa and the high financial cost of DOACs prescribing make it difficult to obtain widespread access for patients [5]. For such reasons, VKAs continue to be the most frequently used OAC in Spain, despite the need for routine blood tests and an exquisite clinical control [6]. Further, it is vital that patients demonstrate adequate self-care, along with treatment concordance and sufficient knowledge to avoid or mitigate adverse effects, to maintain the effectiveness of this treatment.

With these requirements in place, health literacy (HL) could be an essential factor for the self-management of anticoagulation treatment, in line with other cardiovascular diseases [7]. Conceptually, HL encompasses different aspects such as empowerment, as well as competencies to understand, evaluate and use health information to make decisions, including the use of health services [8]. Some preliminary studies exploring the effect of HL on awareness about AF and medication concordance have demonstrated that people with inadequate or insufficient levels of HL have poorer health outcomes, have less knowledge about their health problems and diseases, use preventive services less, and suffer from higher mortality [9, 10].

So far, HL has been linked to the health conditions and outcomes of people with cardiovascular disease. Therefore, we believe that effective self-care, adherence to treatment with oral anticoagulants and prevention of complications could be directly related to the level of health literacy.

However, the existing literature has directly associated higher levels of HL with greater knowledge of the disease, but the association among HL, adherence to anticoagulant therapy and the occurrence of adverse events has presented highly variable results and studies have been scarce [11].

Because of this, we propose identifying the level of HL in the local population on anticoagulation treatment and exploring the relationship between $\mathrm{HL}$ and several health and clinical outcomes. In addition, our work will provide information about the relationship between the different dimensions that make up HL, including the social dimension as a novel aspect, and compliance with OAC treatment, INR control and the occurrence of complications.

\section{Methods}

Study design

Observational, analytic and cross-sectional study.

\section{Population}

We focused on 6 areas within the Xàtiva/Ontinyent Health Department (Valencia, Spain), which were randomly selected from the 17 areas of the department (chose 6 numbers at random, choosing the areas that corresponded with the number extracted). During the study period (January 1, 2018 to April 30, 2019), all patients who came to the nursing consultation were invited to fill out the HL questionnaire. For a population of $N=$ 730 patients (data provided by the health department's pharmacy service), the smallest representative sample we calculated is 252 patients (confidence level 95\%, margin of error 5\%, population proportion 50\%). Recruitment ended after reaching the minimum representative study sample (because the questionnaire was long, with complex questions and patients in many cases refused to stay and wait 15-20 min more in the health centre).

The eligibility criteria were: Patients who are between 50 and 85 years old, have cardiovascular disease, mainly arrhythmias (atrial fibrillation or flutter) or valvular disease, and have received VKAs treatment for at least 6 months. Exclusion criteria included vision or hearing impairment that prevented the completion of the HL questionnaire, illiteracy, discontinued treatment with VKAs, severe neurocognitive or mental health problems that prevented the patient from understanding their pathological conditions, and finally patients whose treatment with VKAs was administered by another person. Methods of selection of participants were to offer participation in the study to all patients who came to the nursing consultation (both on a scheduled and on demand) and met the selection criteria.

The study was conducted in rural areas with a population of 2300 to 8000 inhabitants in each primary health care center, where the distance to the health care center is usually short and can be reached on foot by most citizens.

\section{Study assessment parameters}

Data were obtained on the following variables:

- Socio-demographic: Age, sex, educational level (without studies/basic education/university 
education) and self-perceived social class (low/ medium/high).

- Clinical: Main diagnosis, obesity (BMI > 30), high blood pressure (HBP), polypharmacy (prescription $\geq 5$ drugs), tobacco use (non-smoker/smoker) and occurrence of complications (emergency care or unscheduled hospital admissions during the previous six months).

- VKA treatment: Years of treatment, reporting of VKA treatment by patients to other health professionals, number of controls in 6 months, control of VKA treatment [good control if 65\% INR measurements within range, with measurement by direct method, for at least 6 months] $[1,2]$

- HL: The Health Literacy Questionnaire (HLQ) [12] was used to assess the level of HL. This questionnaire assesses 9 different dimensions, consists of 44 items and has been validated for Spanish speakers.

- Dimension 1 (D1): Feeling understood and supported by health care providers.

- Dimension 2 (D2): Having enough information to manage my health.

- Dimension 3 (D3) Actively managing my health.

- Dimension 4 (D4) Social health support.

- Dimension 5 (D5) Assessment of health information.

- Dimension 6 (D6) Ability to actively participate with health care providers.

- Dimension 7 (D7) Navigation through the health system.

- Dimension 8 (D8) Ability to find good health information.

- Dimension 9 (D9) Understanding health information well enough to know what to do.

The scores for dimensions 1 to 5 are set to four values (completely disagree/disagree/agree/strongly agree), and the scores for dimensions 6 to 9 are set to 5 values (cannot be done or always have difficulties/usually difficult/ Sometimes difficult/ usually have ease/ always have ease). According to the author's request, an independent score was established for each dimension [13].

Sociodemographic variables were collected by means of a patient interview, while clinical variables and those referring to anticoagulant treatment with VKA were collected from the medical records and prescriptions. With regard to the health literacy variable, the questionnaire was administered to patients by means of a direct interview with the principal investigator.

\section{Statistical analysis}

To analyse quantitative variables were used central tendency and dispersion measures. Absolute and relative frequencies, expressed in percentages, were used for qualitative variables. Parametric and non-parametric tests were performed to evaluate the relationship between different variables and dimensions of HLQ. The statistical significance level was determined to be $p<$ 0.05. Were analysed all data using SPSS Statistics for Windows (version 23, Spanish, Armonk, NY, IBM).

\section{Ethical considerations}

The study was approved by the Ethics and Clinical Research Committee of the Primary Care Region of Valencia (Ref.ACC-ACE-2016-01). All participants have provided their written consent to participate in the study and the data of the patients included in the study have been anonymized at all times.

\section{Results}

\section{Description of the sample}

The response rate was 35\% (252 patients responded to the questionnaire). The average age was $74.3+/-7.3$ years, with $\sim 90 \%$ over 65 -years old. Forty-two percent were women, and $74.9 \%$ had AF as primary diagnosis. With respect to their educational level, $50 \%$ of participants had basic studies, while $40.1 \%$ did not. Of the 252 participants, $49.2 \%$ had complications and $11.9 \%$ required hospital admission (Table 1 ).

\section{Relationships between $\mathrm{HL}$ dimensions and variables}

The average score of the participants on each $\mathrm{HL}$ dimension was slightly higher than expected (average of the scale) in all dimensions (Table 2), but mainly in dimension D4. The relationship between the HL dimensions and the different study variables is presented in Tables 3 and 4.

The ANOVA calculations of the different HL dimensions according to the level of studies were statistically significant, indicating differences in scores between two or more of the study level groups. The results showed that D2, D3, D5, D6, D7, D8 and D9 had differences between the three study level groups. The "without studies" group obtained the lowest mean scores on all dimensions, in contrast to the "university education" group with higher means.

For social class, all Kruskal-Wallis tests of the different HL dimensions were statistically significant $(p<.05)$ implying differences in scores between two or more social class groups. Dimensions D5, D8 and D9, were explained by social class at $13-17 \%$, suggesting a large social class effect on these dimensions. D5 and D9 showed differences between all social class groups, with lower median scores for lower-class than middle-class participants. In turn, the median scores in the middle class group were lower than those obtained by participants from the higher socioeconomic stratum. 
Table 1 Characteristics of participants $(n=252)$

\begin{tabular}{|c|c|c|c|}
\hline & & $M / n$ & $\mathrm{Sd} / \%$ \\
\hline \multirow[t]{3}{*}{ Age } & & 74.38 & 7.35 \\
\hline & $<65$ years & 26 & $10.3 \%$ \\
\hline & $=>65$ years & 226 & $89.7 \%$ \\
\hline \multirow[t]{2}{*}{ Sex } & Woman & 107 & $42.5 \%$ \\
\hline & Man & 145 & $57.5 \%$ \\
\hline \multirow[t]{3}{*}{ Education Level } & Without Studies & 101 & $40.1 \%$ \\
\hline & Basic Education & 126 & $50.0 \%$ \\
\hline & Higher Education & 25 & $9.9 \%$ \\
\hline \multirow[t]{3}{*}{ Social Class } & Low & 33 & $13.1 \%$ \\
\hline & Middle & 206 & $81.7 \%$ \\
\hline & High & 13 & $5.2 \%$ \\
\hline \multirow[t]{4}{*}{ Main Diagnosis } & Atrial Fibrillation & 188 & $74.9 \%$ \\
\hline & Atrial Flutter & 7 & $2.8 \%$ \\
\hline & Aortic Prosthesis & 33 & $13.1 \%$ \\
\hline & Mitral Prosthesis & 23 & $9.2 \%$ \\
\hline Years of treatment & & 7.6 & 6.79 \\
\hline \multirow[t]{2}{*}{ Good control of acenocoumarol } & No & 114 & $45,2 \%$ \\
\hline & Yes & 138 & $54,8 \%$ \\
\hline \multirow[t]{2}{*}{ Appearance of complications } & No & 128 & $50.8 \%$ \\
\hline & Yes & 124 & $49.2 \%$ \\
\hline \multirow[t]{2}{*}{ Emergency assistance last 6 months } & No & 129 & $51.2 \%$ \\
\hline & Yes & 123 & $48.8 \%$ \\
\hline \multirow[t]{2}{*}{ Hospital admission last 6 months } & No & 222 & $88.1 \%$ \\
\hline & Yes & 30 & $11.9 \%$ \\
\hline \multirow[t]{2}{*}{ Polypharmacy } & No & 86 & $34.1 \%$ \\
\hline & Yes & 166 & $65.9 \%$ \\
\hline
\end{tabular}

$M$ Mean, $n$ number of cases, $S d$ Standard deviation; \%, percentage

For variables related to medication use, there were statistically significant differences for "reports taking acenocoumarol" in all HL dimensions and for "polypharmacy" in all dimensions except D1, D4 and D6 (Table 3). Nonpolymedicated participants and those reporting treatment with VKA had higher mean scores on all dimensions.
Regarding the control of acenocoumarol and frequency of controls, statistically significant differences were obtained in all dimensions of the questionnaire. In all cases, participants with good anticoagulant control and adequate frequency obtained higher averages than those without good control or suboptimal control frequency. Additionally, the analysis indicated a small effect for the control of acenocoumarol and the frequency of controls on D4 scores. An average effect on the D1 scores for VKA control and on the D1 and D6 dimensions for proper control frequency is shown. Finally, there was a large effect on the scores of the other HL dimensions for drug control and control frequency (Table 4).

In relation to cardiovascular disease risk factors, tobacco use and HBP showed no statistically significant differences $(p>.05)$ on any dimension. In contrast, statistically significant differences in the D5, D8 and D9 dimensions were observed in obese participants, with lower mean scores for these participants.

The occurrence of complications presented $(p<.05)$ in the scores of all dimensions of the HL questionnaire. In all cases, the scores of patients without complications were higher (Table 4). The same was true for emergency department attendance in the previous 6 months. In both cases, a very large effect size was shown in all HL dimensions except D1, D4 and D6.

Finally, hospital admissions showed statistically significant differences $(p<.05)$ in all dimensions for unscheduled hospitalizations in the previous 6 months, except in dimension D4. In all cases, the mean scores of patients with unscheduled hospital admissions were lower than in the rest of the patients (Table 4).

\section{Discussion}

In our study in patients with cardiovascular pathology, health literacy actively influenced the adequate self-management of anticoagulation treatment, the appearance of complications and the unscheduled use of health services. Patients with higher scores on HL

Table 2 Average score of HL dimensions

\begin{tabular}{lllllllll}
\hline Dimension & Mean & Standard error of the mean & Standard deviation & Median & Maximum & Minimum & 25 Percentile & 75 Percentile \\
\hline Dimension 1 & 3.201 & .027 & .429 & 3.125 & 4.000 & 1.500 & 3.000 & 3.500 \\
Dimension 2 & 2.657 & .033 & .517 & 2.750 & 4.000 & 1.000 & 2.250 & 3.000 \\
Dimension 3 & 2.817 & .032 & .511 & 2.800 & 4.000 & 1.000 & 2.600 & 3.000 \\
Dimension 4 & 3.494 & .028 & .437 & 3.600 & 4.000 & 1.400 & 3.200 & 3.800 \\
Dimension 5 & 2.387 & .043 & .686 & 2.400 & 4.000 & 1.000 & 2.000 & 2.800 \\
Dimension 6 & 4.106 & .038 & .596 & 4.200 & 5.000 & 1.200 & 3.800 & 4.600 \\
Dimension 7 & 3.507 & .041 & .654 & 3.667 & 5.000 & 1.167 & 3.083 & 4.000 \\
Dimension 8 & 3.052 & .054 & .851 & 3.200 & 5.000 & 1.000 & 2.400 & 3.800 \\
Dimension 9 & 3.268 & .055 & .871 & 3.400 & 5.000 & 1.400 & 2.600 & 4.000 \\
\hline
\end{tabular}


Table 3 Relationship and statistical significance between variables and HL dimensions

\begin{tabular}{|c|c|c|c|c|c|c|c|c|c|c|}
\hline & & D1 & D2 & D3 & D4 & D5 & D6 & D7 & D8 & D9 \\
\hline $\operatorname{Age}^{D}$ & Sig. & .022 & -.105 & -.104 & -.030 & $-.223^{* *}$ & -.118 & $-.189^{*}$ & $-.282^{* *}$ & $-.261^{* *}$ \\
\hline \multirow[t]{2}{*}{$<65$ years } & Mean (SD) & $3.18(0.4)$ & $2.73(0.47)$ & $2.86(0.58)$ & $3.48(0.33)$ & $2.59(0.78)$ & $4.35(0.49)$ & $3.74(0.58)$ & $3.42(0.76)$ & $3.59(0.85)$ \\
\hline & Median (IQR) & $3.13(0.50)$ & $2.75(0.50)$ & $3.00(0.80)$ & $3.40(0.60)$ & $2.60(1.20)$ & $4.40(1.00)$ & $3.83(0.67)$ & $3.50(1.20)$ & $3.80(1.60)$ \\
\hline \multirow[t]{2}{*}{$=>65$ years } & Mean (SD) & $3.2(0.43)$ & $2.65(0.52)$ & $2.81(0.5)$ & $3.5(0.45)$ & $2.36(0.67)$ & $4.08(0.6)$ & $3.48(0.66)$ & $3.01(0.85)$ & $3.23(0.87)$ \\
\hline & Median (IQR) & $3.13(0.50)$ & $2.75(0.75)$ & $2.80(0.40)$ & $3.60(0.60)$ & $2.40(0.80)$ & $4.20(0.60)$ & $3.50(1.00)$ & $3.00(1.20)$ & $3.40(1.60)$ \\
\hline $\operatorname{Sex}^{A}$ & Sig. & .496 & .055 & .298 & .137 & .096 & .217 & .142 & $028^{*}$ & $.015^{*}$ \\
\hline \multirow[t]{2}{*}{ Woman } & Mean (SD) & $3.18(0.46)$ & $2.58(0.54)$ & $2.78(0.53)$ & $3.44(0.5)$ & $2.3(0.7)$ & $4.05(0.64)$ & $3.44(0.66)$ & $2.92(0.84)$ & $3.11(0.85)$ \\
\hline & Median (IQR) & $3.00(0.50)$ & $2.50(0.75)$ & $2.80(0.40)$ & $3.60(0.60)$ & $2.40(1.00)$ & $4.00(1.00)$ & $3.50(1.00)$ & $3.00(1.40)$ & $3.20(1.40)$ \\
\hline \multirow[t]{2}{*}{ Man } & Mean (SD) & $3.22(0.4)$ & $2.71(0.5)$ & $2.85(0.5)$ & $3.53(0.38)$ & $2.45(0.67)$ & $4.15(0.56)$ & $3.56(0.65)$ & $3.15(0.85)$ & $3.38(0.87)$ \\
\hline & Median (IQR) & $3.25(0.50)$ & $2.75(0.75)$ & $2.80(0.60)$ & $3.60(0.40)$ & $2.40(0.80)$ & $4.20(0.80)$ & $3.67(0.83)$ & $3.20(1.20)$ & $3.40(1.40)$ \\
\hline Education Level ${ }^{B, C}$ & Sig. & $<.001^{* *}$ & $<.001^{* *}$ & $<.001^{* *}$ & $.016^{*}$ & $<.001^{* *}$ & $<.001^{* *}$ & $<.001^{* *}$ & $<.001^{* *}$ & $<.001^{* *}$ \\
\hline \multirow[t]{2}{*}{ Without Studies } & Mean (SD) & $3.06(0.4)$ & $2.33(0.43)$ & $2.51(0.45)$ & $3.42(0.41)$ & $1.94(0.54)$ & $3.85(0.60)$ & $3.08(0.54)$ & $2.38(0.57)$ & $2.56(0.58)$ \\
\hline & Median (IQR) & $3.00(0.25)$ & $2.25(0.5)$ & $2.60(0.60)$ & $3.60(0.60)$ & $2.00(0.80)$ & $4.00(0.60)$ & $3.17(0.83)$ & $2.40(0.80)$ & $2.40(0.80)$ \\
\hline \multirow[t]{2}{*}{ Basic Education } & Mean (SD) & $3.28(0.44)$ & $2.83(0.47)$ & $2.96(0.42)$ & $3.52(0.47)$ & $2.58(0.56)$ & $4.23(0.53)$ & $3.72(0.57)$ & $3.39(0.66)$ & $3.62(0.67)$ \\
\hline & Median (IQR) & $3.25(0.50)$ & $3.00(0.5)$ & $3.00(0.40)$ & $3.80(0.40)$ & $2.60(0.60)$ & $4.20(0.60)$ & $3.83(0.50)$ & $3.60(1.00)$ & $3.80(0.60)$ \\
\hline \multirow[t]{2}{*}{ Higher Education } & Mean & $3.4(0.36)$ & $3.11(0.32)$ & $3.36(0.39)$ & $3.67(0.26)$ & $3.26(0.56)$ & $4.54(0.49)$ & $4.16(0.42)$ & $4.06(0.63)$ & $4.35(0.49)$ \\
\hline & Median (IQR) & $3.25(0.50)$ & $3.00(0.25)$ & $3.20(0.80)$ & $3.80(0.20)$ & $3.20(1.00)$ & $4.60(0.60)$ & $4.00(0.33)$ & $4.00(0.80)$ & $4.40(0.60)$ \\
\hline Social Class ${ }^{c}$ & Sig. & $.019 *$ & $<.001^{* *}$ & $<.001^{* *}$ & $.003^{*}$ & $<.001^{* *}$ & $<.001 * *$ & $<.001 * *$ & $<.001^{* *}$ & $<.001^{* *}$ \\
\hline \multirow[t]{2}{*}{ Low } & Mean (SD) & $2.98(0.44)$ & $2.3(0.39)$ & $2.41(0.53)$ & $3.38(0.39)$ & $1.81(0.55)$ & $3.76(0.56)$ & $3.04(0.58)$ & $2.25(0.64)$ & $2.43(0.61)$ \\
\hline & Median (IQR) & $3.00(0.50)$ & $2.25(0.50)$ & $2.4(0.80)$ & $3.40(0.40)$ & $1.80(0.80)$ & $3.80(0.80)$ & $3.00(0.67)$ & $2.20(0.40)$ & $2.20(0.80)$ \\
\hline \multirow[t]{2}{*}{ Middle } & Mean (SD) & $3.23(0.42)$ & $2.71(0.51)$ & $2.87(0.49)$ & $3.5(0.45)$ & $2.45(0.66)$ & $4.15(0.59)$ & $3.56(0.65)$ & $3.14(0.82)$ & $3.35(0.83)$ \\
\hline & Median (IQR) & $3.25(0.50)$ & $2.75(0.75)$ & $3.00(0.60)$ & $3.60(0.60)$ & $2.60(0.80)$ & $4.20(0.80)$ & $3.67(0.83)$ & $3.20(1.20)$ & $3.40(1.40)$ \\
\hline \multirow[t]{2}{*}{ High } & $\mathrm{Mec}$ & 3.27 & 2.7 & $3(0.34)$ & $(0.29)$ & $0.67)$ & $4.34(0.51)$ & 3.9 & $3.66(0.64)$ & $4.10(0.56)$ \\
\hline & Median (IQR) & $3.25(0.50)$ & $2.75(0.25)$ & $3.00(0.20)$ & $3.80(0.0)$ & $3.00(0.40)$ & $4.20(0.60)$ & $4.00(0.17)$ & $4.00(0.80)$ & $4.20(0.20)$ \\
\hline Polypharmacy ${ }^{\mathrm{A}}$ & Sig. & .255 & $<.001^{* *}$ & $.005^{*}$ & .780 & $<.001^{* *}$ & .367 & $.004 *$ & $<.001^{* *}$ & $<.001^{* *}$ \\
\hline \multirow[t]{2}{*}{ No } & Mean (SD) & $3.24(0.4)$ & $2.82(0.46)$ & $2.94(0.58)$ & $3.48(0.4)$ & $2.62(0.68)$ & $4.15(0.63)$ & $3.67(0.64)$ & $3.4(0.83)$ & $3.58(0.84)$ \\
\hline & Median (IQR) & $3.25(0.50)$ & $3.00(0.50)$ & $3.00(0.40)$ & $3.60(0.60)$ & $2.60(0.60)$ & $4.20(0.80)$ & $3.83(0.50)$ & $3.60(1.20)$ & $3.80(1.00)$ \\
\hline \multirow[t]{2}{*}{ Yes } & Mean (SD) & $3.18(0.44)$ & $2.57(0.53)$ & $2.75(0.46)$ & $3.5(0.46)$ & $2.26(0.66)$ & $4.08(0.58)$ & $3.42(0.65)$ & $2.87(0.81)$ & $3.10(0.84)$ \\
\hline & Median (IQR) & $3.00(0.50)$ & $2.50(0.75)$ & $2.80(0.40)$ & $3.60(0.60)$ & $2.40(1.00)$ & $4.10(0.60)$ & $3.33(0.83)$ & $2.80(1.40)$ & $3.10(1.40)$ \\
\hline Obesity ${ }^{A}$ & Sig. & .895 & .288 & .113 & .525 & $.030^{*}$ & .318 & .142 & $.030^{*}$ & $.018^{*}$ \\
\hline \multirow[t]{2}{*}{ No } & Mean (SD) & $3.2(0.43)$ & $2.69(0.52)$ & $2.86(0.51)$ & $3.48(0.45)$ & $2.46(0.7)$ & $4.14(0.55)$ & $3.56(0.65)$ & $3.15(0.84)$ & $3.38(0.86)$ \\
\hline & Median (IQR) & $3.13(0.50)$ & $2.75(0.75)$ & $2.80(0.60)$ & $3.60(0.60)$ & $2.60(1.00)$ & $4.20(0.80)$ & $3.67(0.83)$ & $3.20(1.30)$ & $3.40(1.30)$ \\
\hline \multirow[t]{2}{*}{ Yes } & Mean (SD) & $3.2(0.42)$ & $2.62(0.52)$ & $2.76(0.51)$ & $3.52(0.41)$ & $2.28(0.65)$ & $4.06(0.66)$ & $3.43(0.66)$ & $2.91(0.86)$ & $3.11(0.86)$ \\
\hline & Median (IQR) & $3.13(0.50)$ & $2.50(0.75)$ & $2.80(0.50)$ & $3.60(0.50)$ & $2.40(1.00)$ & $4.20(0.60)$ & $3.50(0.83)$ & $3.00(1.50)$ & $3.20(1.50)$ \\
\hline
\end{tabular}

${ }^{*} p<.05 ;{ }^{* *} p<.001$; A, T-Student tests; B, Anova; C, Kruskal-Wallis; D,Mann-Whitney U; SD, Standar desviation; IQR, Interquartile range

dimensions had better control of OAC treatment and optimal frequency of visits. They also reported confidence about their information management skills, empowerment, and self-efficacy, presenting better selfcare. These results coincide with those demonstrated by some authors [14-17].

Therapeutic concordance with OACs was significantly related to the scores of all HL dimensions, with $54.8 \%$ of participants presenting an adequate control of OAC treatment. These results are similar to another study carried out in Valencia [18], where 53.9\% presented good control, and slightly higher than the $47.5 \%$ of patients in Time in Therapeutic Range (TTR) in Granada [19]. Reading et al. [20] related inadequate HL to a lack of pharmacological adherence in AF, while another study associated a poor control of VKA (TTR $<50 \%)$ with limited HL, especially in patients over 65 [21]. However, other studies have reported equivocal relations between HL and treatment adherence; for example, HL as measured with the S-TOFHLA scale was associated with 
Table 4 Statistical relationship between variables related to the treatment of OACs and occurrence of complications with $\mathrm{HL}$ dimensions

\begin{tabular}{|c|c|c|c|c|c|c|c|c|c|c|}
\hline & & D1 & D2 & D3 & D4 & D5 & D6 & D7 & D8 & D9 \\
\hline Good VKAs control A & Sig. & $<.001^{* *}$ & $<.001^{* *}$ & $<.001^{* *}$ & $.006^{*}$ & $<.001^{* *}$ & $<.001 * *$ & $<.001 * *$ & $<.001^{* *}$ & $<.001 * *$ \\
\hline No & Mean (SD) & $3.06(0.41)$ & $2.37(0.42)$ & $2.54(0.50)$ & $3.41(0.46)$ & $2.02(0.58)$ & $3.86(0.60)$ & $3.13(0.61)$ & $2.45(0.64)$ & $2.64(0.67)$ \\
\hline Yes & Mean (SD) & $3.31(0.41)$ & $2.89(0.46)$ & $3.04(0.39)$ & $3.56(0.40)$ & $2.68(0.62)$ & $4.30(0.50)$ & $3.81(0.52)$ & $3.54(0.67)$ & $3.77(0.65)$ \\
\hline Adequa & Sig. & $<.001^{* *}$ & $<.001 * *$ & $<.001 * *$ & $.001^{*}$ & $<.001 * *$ & $<.001 * *$ & $<.001^{* *}$ & $<.001^{* *}$ & $<.001 * *$ \\
\hline No & Mean (SD) & $3.06(0.37)$ & $2.36(0.40)$ & $2.50(0.48)$ & $3.37(0.45)$ & $1.97(0.60)$ & $3.86(0.60)$ & $3.12(0.61)$ & $2.46(0.66)$ & $2.66(0.71)$ \\
\hline Yes & Mean (SD) & $3.28(0.44)$ & $2.83(0.50)$ & $3.00(0.42)$ & $3.56(0.41)$ & $2.63(0.60)$ & $4.25(0.54)$ & $3.74(0.56)$ & $3.41(0.74)$ & $3.63(0.74)$ \\
\hline at he takes VKAs ${ }^{D}$ & Sig. & $.027^{*}$ & $.004^{*}$ & $<.001^{* *}$ & $.014^{*}$ & $.005^{*}$ & $.001 *$ & $.005^{*}$ & $<.001^{* *}$ & $<.001 * *$ \\
\hline No & Mean (SD) & $3.00(0.46)$ & $2.32(0.56)$ & $2.28(0.53)$ & $3.30(0.37)$ & $1.99(0.68)$ & $3.71(0.70)$ & $3.16(0.55)$ & $2.33(0.74)$ & 2.60 \\
\hline Yes & Mean (SD) & $3.21(0.41)$ & $2.68(0.49)$ & $2.86(0.46)$ & $3.51(0.43)$ & $2.42(0.67)$ & $4.15(0.56)$ & $3.54(0.63)$ & $3.12(0.82)$ & $3.40(0.83)$ \\
\hline Complications $^{\mathrm{A}}$ & Sig. & $<.001 * *$ & $<.001 * *$ & $<.001^{* *}$ & $.002 *$ & $<.001^{* *}$ & $<.001 * *$ & $<.001^{* *}$ & $<.001^{* *}$ & $<.001 * *$ \\
\hline No & Mean (SD) & $3.31(0.40)$ & $2.91(0.44)$ & $3.05(0.40)$ & $3.57(0.37)$ & $2.74(0.59)$ & $4.31(0.51)$ & $3.85(0.54)$ & $3.60(0.66)$ & $3.82(0.63)$ \\
\hline Yes & Mean (SD) & $3.08(0.41)$ & $2.38(0.44)$ & $2.57(0.49)$ & $3.40(0.48)$ & $2.02(0.57)$ & $3.88(0.59)$ & $3.14(0.55)$ & $2.48(0.61)$ & $2.69(0.68)$ \\
\hline Emergency assistance ${ }^{\mathrm{A}}$ & Sig. & $<.001^{* *}$ & $<.001^{* *}$ & $<.001^{* *}$ & $.002^{*}$ & $<.001^{* *}$ & $<.001 * *$ & $<.001^{* *}$ & $<.001^{* *}$ & $<.001 * *$ \\
\hline No & Mean (SD) & $3.31(0.40)$ & $2.91(0.43)$ & $3.04(0.40)$ & $3.57(0.37)$ & $2.74(0.58)$ & $4.31(0.51)$ & $3.85(0.54)$ & $3.60(0.66)$ & $3.83(0.63)$ \\
\hline Yes & Mean (SD) & $3.08(0.42)$ & $2.38(0.44)$ & $2.57(0.49)$ & $3.40(0.48)$ & $2.01(0.57)$ & $3.88(0.60)$ & $3.13(0.54)$ & $2.47(0.60)$ & $2.67(0.67)$ \\
\hline Hospital admission A & Sig. & $.001^{*}$ & $<.001 * *$ & $<.001^{* *}$ & .073 & $<.001^{* *}$ & $<.001^{* *}$ & $<.001^{* *}$ & $<.001^{* *}$ & $<.001^{* *}$ \\
\hline No & Mean (SD) & $3.23(0.40)$ & $2.70(0.50)$ & $2.86(0.48)$ & $3.51(0.42)$ & $2.44(0.67)$ & $4.16(0.55)$ & $3.57(0.63)$ & $3.15(0.82)$ & $3.36(0.83)$ \\
\hline Yes & Mean (SD) & $2.95(0.54)$ & $2.31(0.48)$ & $2.43(0.54)$ & $3.36(0.47)$ & $1.92(0.58)$ & $3.68(0.70)$ & $3.03(0.57)$ & $2.28(0.64)$ & $2.52(0.77)$ \\
\hline
\end{tabular}

${ }^{*} p<.05$; ${ }^{*} p<.001 ; \mathrm{A}, \mathrm{T}$-Student tests; B, Anova; C, Kruskal-Wallis; D, Mann-Whitney U

OAC treatment adherence but not with TTR [22, 23]. A 2017 study [24] using the SAHLPA scale linked inadequate level of HL to greater cognitive impairment and the need for help to take the treatment properly, but the multivariate analysis could not correlate an inadequate level of HL with having a TTR in the range. It is possible that these studies were unrelated because the scales were only used to evaluate recognition and ability to read certain words, not the different dimensions and skills that comprise HL. Because of this, patients may receive high scores in the scales yet lack more complex treatmentfocused skills.

With respect to the occurrence of complications associated with OAC treatment, our study showed a significant association with scores in all HL dimensions, with higher-scoring patients experiencing fewer complications, lower emergency department attendance and hospitalization rates. Complications occurred in $49.2 \%$ of participants (228 patients), well above the $9 \%$ shown in a 2014 study [25]. This difference could be due to the origin of the information about the occurrence of complications, extracted from medical records in our case, while the 2014 study [25] used patient-reported complications which may have been affected by recall bias, particularly as the study noted that more than $50 \%$ of patients did not recognize emergency situations.

Overall, such results may have been expected as HL dimensions allow people to identify reliable and accurate health information, resolve doubts on their own or with peer support and learn about preventive health services, anticipating and mitigating the occurrence of complications. This perspective is also supported by other authors who associate lower HL with a reduced awareness of AF diagnosis [26], adherence to treatment [20], higher rates of re-hospitalization [27], risk of mortality [27-29] and a decrease in physical and emotional health status [15]. This study [15] also uses the HLQ questionnaire but only evaluated two dimensions, "Understanding health information" and "Engaging with healthcare providers", and suggests that HL is also associated with health behaviours in cardiovascular patients.

In addition to the above variables, a relationship between age, educational or academic level and social class was also observed with HL scores. Younger patients considered themselves capable of identifying accurate information from different sources, even on their own, remaining up-to-date and knowledgeable about health services. These results are consistent with other studies on patients with cardiovascular health problems, which negatively correlated the level of HL with the age of the participants [30-32]. The powerful influence of 'educational' or academic factors on HL, explaining about $60 \%$ of the HL level [31], as well as 'social class' has been extensively described $[14,33,34]$. These findings coincide with our results where these variables presented significance in all dimensions of HL. 
The health outcomes obtained in our study would align well with the WHO's social determinants model, which proposes the 'social origin' of diseases, in turn causing health inequalities. Within this framework, HL has shown its central role as a determinant of health [35]. In fact, low levels of education limit access to better jobs, or nudging persons towards less secure and riskier jobs, with lower incomes and poorer levels of health throughout life [36, 37].

Our research has shown that different health determinants could contribute to inadequate control of anticoagulant therapy. Such determinants would be older age (over 75 years), basic or no education, limited HL (specifically the HL dimensions "Assessment of health information", "Ability to find good health information" and "Understanding health information sufficiently to know what to do"), low social class, obesity, multimorbidity and polypharmacy. This finding allows an early identification of a profile of patients, more vulnerable, who would be most at risk of developing complications, having worse health outcomes.

Further, our study is a pioneer in evaluating the nine dimensions that make up HL in patients on VKAs treatment (only one study has been found that evaluated the HL dimensions in this population and it only assesses two dimensions) and we noted the importance of the "social health support" dimension which showed a higher than expected average score. This dimension assesses a person's social system and measures the following aspects: If I can get access to several people who understand and support me. If when I feel ill, the people around me really understand what I am going through. If I need help, I have plenty of people I can rely on. If I have at least one person who can come to medical appointments with me and if I I have strong support from family or friends.

In our study, this high score could be explained by the environment in which the study was carried out, a mainly rural área where inhabitants would benefit more from social support networks at neighbourhood and family level, less present or weaker in the urban environment, as shown in some studies carried out in Spain on patients with various pathologies [38, 39].

In addition to the novel aspects discussed above, our work establishes a strong relationship between the dimensions of $\mathrm{HL}$ and the social determinants that constitute the axes of inequality in health. It highlights the importance of considering HL as a determinant of health because it is a predictor of individual health status and enables people in vulnerable situations to be identified and health inequalities to be addressed more effectively.

For all these reasons, our study shows how HL intervenes in health behaviours and outcomes, modulating therapeutic concordance and the occurrence of complications in cardiovascular patients. Furthermore, taking into account the social determinants that influence HL, it would be appropriate to establish individual therapeutic measures and community interventions that act synergistically in HL to improve the prevention of cardiovascular disease.

\section{Limitations}

The study was conducted only in a rural population setting, using validated questionnaires for Spanish-speaking people. Routine objective variables have been collected and the sample size was calculated to reach a representative sample of the population. Although participation in the study and completion of the questionnaire was offered to all patients, we were forced to stop the collection when the representative sample was reached and this could be interpreted as a selection bias. Furthermore, the study used a bivariate analysis model, so the results should be taken with caution because the statistical significance could not be demonstrated with variables tested in more powerful analyses, such as multivariate models.

\section{Conclusions}

The importance of the social environment in the health and safety outcomes of VKAs treatment is highlighted. People with higher scores on HL dimensions demonstrated better therapeutic control, lower emergency department attendance and fewer hospital admissions, highlighting the importance of intervening on this determinant because of its consequences on the control of patients with heart disease requiring VKAs treatment.

\section{Abbreviations \\ AF: Atrial fibrillation; CFI: Comparative Fit Index; DOACs: Direct Oral Anticoagulants; D1: Dimension 1; D2: Dimension 2; D3: Dimension 3; D4: Dimension 4; D5: Dimension 5; D6: Dimension 6; D7: Dimension 7; D8: Dimension 8; D9: Dimension 9; HBP: High Blood Pressure; HL: Health Literacy; HLQ: Health Literacy Questionnaire; INR: International Normalized Ratio; OAC: Oral Anticoagulants; RMSEA: Root Mean Square Error of Approximation; SAHLPA: Short Assessment of Health Literacy in Portuguese- speaking Adults; S-TOFHLA: Test of Functional Health Literacy in Adults; TLI: Tucker Lewis Index; TTR: Time in Therapeutic Range; US: United States; VKAs: Vitamin K antagonists; WHO: World Health Organization; WRMR: Weighted Root Mean Square Residual}

\section{Acknowledgements}

Not applicable.

\section{Availability of data and material}

The datasets generated and/or analysed during the current study are available in the Figshare repository.

https://figshare.com/articles/dataset/Data_base_HL_and_OAC_xIsx/14703537

\section{Authors' contributions}

All authors are responsible for the research reported, have seen and approved the manuscript in its final version, as submitted. All authors have contributed significantly to the work. ACG has contributed to design of study, to acquisition and interpretation of dates, drafted the manuscript and critically revised the manuscript. AMS has contributed to conception, to analysis and interpretation of dates and critically revised the manuscript. 
MADH has contributed to design of study; to acquisition, analysis, and interpretation of dates and critically revised the manuscript. VGC and ECS have contributed to conception and design of study, to analysis and interpretation of dates, drafted the manuscript and critically revised the manuscript; VGC and ECS are joint senior authors.

\section{Funding}

This research did not receive any specific grant from any funding agency in the public, commercial or non-profit sectors. ECS is affiliated with the National Institute for Health Research Health Protection Research Unit in Healthcare Associated Infection and Antimicrobial Resistance at Imperial College London in partnership with Public Health England. ECS is a National Institute for Health Research Senior Nurse and Midwife Research Leader, and acknowledges the support of the BRC.

\section{Declarations}

\section{Ethics approval and consent to participate}

The study was approved by the Ethics and Clinical Research Committee of the Primary Care Region of Valencia, Spain (Ref.ACC-ACE-2016-01). Written informed consent was obtained from the participants and the data included in the study was anonymized.

\section{Consent for publication}

Not applicable.

\section{Competing interests}

ECS has been a member of the Editorial Board at BMC Public Health since March 2018. All other authors declare no conflict of interest.

\section{Author details}

${ }^{1}$ Hospital Universitario y politécnico La Fe, Valencia, Spain. ${ }^{2}$ Health Research Institut La Fe, Research Group GREIACC, Valencia, Spain. ${ }^{3}$ Nursing Department, Universitat de València, Valencia, Spain. ${ }^{4}$ Facultat d'Infermeria i Podologia. Nursing Care and Education Research Group. (GRIECE). Grupo Investigación en Cuidados (INCLIVA), Hospital Clínico Universitario, Valencia, Spain. ${ }^{5}$ Direcció d'Atenció Primaria Costa Ponent, Institut Català de la Salut, Avinguda de la Gran via de l'Hospitalet, 199-203, 08908 L'Hospitalet de Llobregat, Barcelona, Spain. 'Unitat de Suport a la Recerca Costa de Ponent, Institut Universitari d'Investigació en Atenció Primària Jordi Gol (IDIAP Jordi Gol), 08940 Cornellà de Llobregat, Spain. ${ }^{7}$ Escuela de Enfermería La Fe, centre affiliated to Universitat de Valencia, Valencia, Spain. ${ }^{8}$ School of Health Sciences, University of London, London, UK. ${ }^{9}$ National Institute for Health Research Health Protection Research Unit in Healthcare-Associated Infections and Antimicrobial Resistance at Imperial College London, London, UK.

Received: 8 September 2020 Accepted: 10 June 2021

Published online: 09 July 2021

\section{References}

1. January CT, Wann LS, Alpert JS, et al. 2014 AHA/ACC/HRS guideline for the management of patients with atrial fibrillation: a report of the american college of cardiology/american heart association task force on practice guidelines and the heart rhythm society. J Am Coll Cardiol. 2014;64(21):1.

2. Kirchhof P, Benussi S, Kotecha D, Ahlsson A, Atar D, Casadei B, et al. 2016 ESC guidelines for the management of a trial fibrillation developed in collaboration with EACTS. Eur Heart J. 2016;37(38):2893-962. https://doi. org/10.1093/eurheartj/ehw210.

3. Gosselin RC, Roberts AJ, Dager WE. The joint commission national patient safety goals (NPSG) directing anticoagulation safety in the united states. Annals of Blood. 2019;4:21.

4. Mould H, UI-Haq M, Thachil J. The ups and downs of anticoagulation prescription in the united kingdom. Annals of Blood. 2019;4:18.

5. Bonet Pla Á, Gosalbes Sóler V, Ridao-López M, Navarro Pérez J, Navarro Cubells B, Peiró S. Dabigatrón versus acenocumarol para la prevención del ictus en la fibrilación atrial: Análisis de impacto presupuestario en un departamento sanitario. Revista Española de Salud Pública. 2013;87(4):33142. https://doi.org/10.4321/S1135-57272013000400004.

6. Moreno-Arribas J, Bertomeu-González V, Anguita-Sanchez M, Cequier Á Muñiz J, Castillo J, et al. Choice of new oral anticoagulant agents versus vitamin K antagonists in atrial fibrillation: FANTASIIA study. J Cardiovasc Pharmacol Ther. 2016;21(2):150-6. https://doi.org/10.1177/1074248415596426.

7. Dennison CR, McEntee ML, Samuel $L$, et al. Adequate health literacy is associated with higher heart failure knowledge and self-care confidence in hospitalized patients. J Cardiovasc Nurs. 2011;26(5):359-67. https://doi.org/1 0.1097/JCN.0b013e3181f16f88.

8. Sorensen K, Van den Broucke S, Fullam J, et al. Health literacy and public health: a systematic review and integration of definitions and models. BMC Public Health. 2012;12(1):80. https://doi.org/10.1186/1471-2458-12-80.

9. Bostock S, Steptoe A. Association between low functional health literacy and mortality in older adults: longitudinal cohort study. BMJ. 2012; 344(mar15 3):e1602.https://doi.org/10.1136/bmj.e1602.

10. DeWalt DA, Berkman ND, Sheridan S, Lohr KN, Pignone MP. Literacy and health outcomes. J Gen Intern Med. 2004;19(12):1228-39. https://doi.org/1 0.1111/j.1525-1497.2004.40153.x.

11. Cabellos-García AC, Martínez-Sabater A, Castro-Sánchez E, Kangasniemi M, Juárez-Vela R, Gea-Caballero V. Relation between health literacy, self-care and adherence to treatment with oral anticoagulants in adults: a narrative systematic review. BMC Public Health. 2018:18(1):1-12.

12. Osborne RH, Batterham RW, Elsworth GR, Hawkins M, Buchbinder R. The grounded psychometric development and initial validation of the health literacy questionnaire (HLQ). BMC Public Health. 2013;13(1):658. https://doi. org/10.1186/1471-2458-13-658

13. Jessup RL, Osborne RH, Beauchamp A, Bourne A, Buchbinder R. Health literacy of recently hospitalised patients: a cross-sectional survey using the health literacy questionnaire (HLQ). BMC Health Serv Res. 2017;17(1):52-64. https://doi.org/10.1186/s12913-016-1973-6.

14. Aaby A, Friis K, Christensen B, Rowlands G, Maindal HT. Health literacy is associated with health behaviour and self-reported health: a large population-based study in individuals with cardiovascular disease. Eur J Prev Cardiol. 2017;24(17):1880-8. https://doi.org/10.1177/2047487317729538.

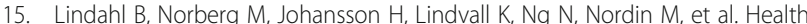
literacy is independently and inversely associated with carotid artery plaques and cardiovascular risk. Eur J Prev Cardiol. 2020;27(2):209-15. https://doi.org/10.1177/2047487319882821.

16. Wu J, Holmes GM, DeWalt DA, et al. Low literacy is associated with increased risk of hospitalization and death among individuals with heart failure. J Gen Intern Med. 2013;28(9):1174-80. https://doi.org/10.1007/s11 606-013-2394-4

17. Rolls CA, Obamiro KO, Chalmers L, Bereznicki LRE. The relationship between knowledge, health literacy, and adherence among patients taking oral anticoagulants for stroke thromboprophylaxis in atrial fibrillation. Cardiovasc Ther. 2017:35(6):e12304

18. Boned-Ombuena A, Pérez-Panadés J, López-Maside A, Miralles-Espí M, Guardiola Vilarroig S, Adam Ruiz D, et al. Prevalencia de la anticoagulación oral y calidad de su seguimiento en el ámbito de la atención primaria: Estudio de la red centinela sanitaria de la comunitat valenciana. Atención Primaria. 2017:49(9):534-48. https://doi.org/10.1016/j.aprim.2016.11.015

19. Fernández López P, López Ramiro Ml. Merino de Haro I Cedeño Manzano G, Díaz Siles FJ, Hermoso Sabio A. Estado de control de pacientes en tratamiento con anticoagulantes orales antagonistas de la vitamina $\mathrm{K}$ en atención primaria. estudio ECOPAVIK. Semergen. 2016;42(8):530-7. https:// doi.org/10.1016/j.semerg.2015.12.006.

20. Reading SR, Black MH, Singer DE, et al. Risk factors for medication nonadherence among atrial fibrillation patients. BMC Cardiovasc Disord. 2019; 19(1):38. https://doi.org/10.1186/s12872-019-1019-1.

21. Oramasionwu CU, Bailey SC, Duffey KE, Shilliday BB, Brown LC, Denslow SA, et al. The association of health literacy with time in therapeutic range for patients on warfarin therapy. J Health Commun. 2014;19(Suppl 2):19-28. https://doi.org/10.1080/10810730.2014.934934.

22. Schillinger D, Wang F, Rodriguez M, Bindman A, Machtinger EL. The importance of establishing regimen concordance in preventing medication errors in anticoagulant care. J Health Commun. 2006;11(6):555-67. https:// doi.org/10.1080/10810730600829874.

23. Fang MC, Machtinger EL, Wang F, Schillinger D. Health literacy and anticoagulation-related outcomes among patients taking warfarin. J Gen Intern Med. 2006;21(8):841-6. https://doi.org/10.1111/j.1525-1497.2006. 00537x

24. Martins MAP, Costa JM. Mambrini, Juliana Vaz de Melo, et al. health literacy and warfarin therapy at two anticoagulation clinics in Brazil. Heart. 2017 103(14):1089-95. https://doi.org/10.1136/heartjnl-2016-310699. 
25. Chenot J, Hua TD, Abu Abed M, et al. Safety relevant knowledge of orally anticoagulated patients without self-monitoring: a baseline survey in primary care. BMC Fam Pract. 2014;15(1):104-12. https://doi.org/10.1186/14 71-2296-15-104.

26. Reading SR, Go AS, Fang MC, et al. Health literacy and awareness of atrial fibrillation. J Am Heart Assoc. 2017;6(4):1-11.

27. Peterson PN, Shetterly SM, Clarke CL, Bekelman DB, Chan PS, Allen LA, et al. Health literacy and outcomes among patients with heart failure. JAMA. 2011;305(16):1695-701. https://doi.org/10.1001/jama.2011.512.

28. McNaughton CD, Cawthon C, Kripalani S, Liu D, Storrow AB, Roumie CL. Health literacy and mortality: A cohort study of patients hospitalized for acute heart failure. J Am Heart Assoc. 2015;4(5):e001799.

29. Oscalices MIL, Okuno MFP, Lopes MCBT, REA B, CRV C. Health literacy and adherence to treatment of patients with heart failure. Rev Esc Enferm USP. 2019:53:e03447

30. Fabbri M, Yost K, Finney Rutten L, Manemann SM, Boyd CM, Jensen D, et al. Health literacy and outcomes in patients with heart failure: a prospective community study. Mayo Clin Proc. 2018;93(1):9-15. https://doi. org/10.1016/j.mayocp.2017.09.018.

31. Santesmases-Masana R, González-de Paz L, Real J, Borràs-Santos A, SisóAlmirall A, Navarro-Rubio MD. Alfabetización en salud en pacientes con insuficiencia cardiaca atendidos en atención primaria. Atención Primaria. 2017;49(1):28-34. https://doi.org/10.1016/j.aprim.2016.03.003.

32. Montesi M. Alfabetización en salud: Revisión narrativa e interdisciplinar de la literatura publicada en biomedicina y en biblioteconomía y documentación. Revista Cubana de Información en Ciencias de la Salud. 2017:28(3):1-21.

33. Van der Heide I, Wang J, Droomers M, Spreeuwenberg P, Rademakers J, Uiters $\mathrm{E}$. The relationship between health, education, and health literacy: results from the dutch adult literacy and life skills survey. J Health Commun. 2013;18(Suppl 1):172-84. https://doi.org/10.1080/10810730.2013.825668.

34. Greenberg KL, Leiter E, Donchin M, Agbaria N, Karjawally M, Zwas DR. Cardiovascular health literacy and patient-physician communication intervention in women from disadvantaged communities. Eur J Prev Cardiol. 2019;26(16):1762-70. https://doi.org/10.1177/2047487319853900.

35. Cabellos-García AC, Castro-Sánchez E, Martínez-Sabater A, Díaz-Herrera MÁ, Ocaña-Ortiz A, Juárez-Vela R, et al. Relationship between determinants of health, equity, and dimensions of health literacy in patients with cardiovascular disease. Int J Environ Res Public Health. 2020;17(6):2082. https://doi.org/10.3390/ijerph17062082.

36. Davis SN, Wischhusen JW, Sutton SK, et al. Demographic and psychosocial factors associated with limited health literacy in a community-based sample of older black americans. Patient Educ Couns. 2020;103(2):385-91.

37. Fleary SA, Ettienne R. Social disparities in health literacy in the United States. Health Lit Res Pract. 2019;3(1):e47-52.https://doi.org/10.3928/24748307-201 90131-01.

38. Monreal Bosch P, del Valle Gómez A. Los grandes olvidados: Las personas mayores en el entorno rural. Psychosoc Interv. 2009;18(3):269-77. https:// doi.org/10.5093/in2009v18n3a7.

39. Sanchez Oro Sanchez M, Pérez Rubio JA, Moreno Ramos J. Los mayores en el continuo rural-urbano. Aproximación a la percepción subjetiva y expectativas vitales (el caso de extremadura). Papers Revista de Sociologia. 2012;98(1):143

\section{Publisher's Note}

Springer Nature remains neutral with regard to jurisdictional claims in published maps and institutional affiliations.

Ready to submit your research? Choose BMC and benefit from:

- fast, convenient online submission

- thorough peer review by experienced researchers in your field

- rapid publication on acceptance

- support for research data, including large and complex data types

- gold Open Access which fosters wider collaboration and increased citations

- maximum visibility for your research: over $100 \mathrm{M}$ website views per year

At BMC, research is always in progress.

Learn more biomedcentral.com/submissions 